\title{
Resistance to Co-Amoxiclav (Augmentin) in Community-Acquired and Nosocomial Pleural Infections
}

\section{Sébastien Champion* and Marianne Annonay}

Department of Medical and Toxicological Intensive Care Unit, Lariboisière University Hospital, 75010 Paris, France

\begin{abstract}
Objective: To describe the ecology in pleural infections, where nosocomial and community-acquired infections may have different ecology.

Methods: retrospective single center study. Any subject admitted in intensive care unit with a diagnosis of complicated pleural effusion (presence of macroscopic pus, or sero-fibrinous pleural effusion with $\mathrm{pH}<7.2$ or LDH $>1000$ or pleural glucose $<0,4 \mathrm{~g} / \mathrm{L}$, and signs of infection or positive bacteriological sampling) were included.

Results: From 2006 to 2012, 57 patients were included. Four strains of "Multi-resistant" bacteria were reported in 3 patients with community-acquired pleural infection. As a whole 3 out of $57(5 \%)$ patients had microorganisms (not including candida and mycobacteria) resistant to co-amoxiclav. It was not different between nosocomial and community-acquired pleural infections.
\end{abstract}

Conclusion: Our study found resistance to co-amoxiclav in $14 \%$ and "multi-drug resistance" in $8 \%$ of the patients with community-acquired pleural infection.

Keywords: Empyema; Nosocomial; Pleural; Infection; Antibiotics; Co-amoxiclav; Thoracocentesis

\section{Introduction}

Empyema thoracis are rarely seen in the intensive care unit (ICU). They are reported to correspond to an unfavorable evolution of lung infection [1]. Bacterial ecology was largely described in ancient series [2-4]. The flora found in the condition of community-acquired was gladly polymorphic and often included Gram-positive cocci and anaerobes. This feature was acknowledged in more recent studies $[5,6]$. In empyema thoracis, systemic antibiotic therapy is recommended. However, the choice of the antibiotics is still matter of debate, including recommendation of the association of penicillin with a betalactamase inhibitor for community-acquired pleural infections $[7,8]$. However, recently, the resistant bacteria encountered in nosocomial thoracic empyema was emphasized, in up to $40 \%$ of the patients $[6,9]$. Consequently, owing to the expansion of the use of antibiotics and the frequent "multi-resistant" bacteria, increasing surveillance of susceptibility of the bacteria should be considered. Indeed, significant increase in mortality rate related to empyema was noticed in a study over 100 years. The authors speculated that changes in microorganisms, with perhaps more antibiotic resistance, might cause this increased mortality rate [10]. Accordingly, increased numbers of pleural infections due to Staphylococcus aureus [11,12], Streptococcus milleri [1], and Pseudomonas aeruginosa $[11,13]$ was acknowledged.

\section{Purpose of the study}

To describe the ecology in empyema thoracis and complicated pleural effusion, and resistance to common antibiotics with emphasize on sensitivity to co-amoxiclav.

\section{Material and Methods}

\section{Patients}

The research protocol was consistent with the declaration of Helsinki and was approved by Ethics Committee. Over a period of 6 years, from 2006 to 1012, any admitted subjects in our medical ICU with a diagnosis of empyema thoracis and/or complicated pleural effusion were retrospectively included according to the following criteria:
-Presence of frank pus in the pleural cavity macroscopically during thoracocentesis, or

-positive bacteriological sample (culture or direct examination) of the pleural fluid (PF), or

-sero-fibrinous pleuritis with a $\mathrm{PF} \mathrm{pH}<7.2$, or $\mathrm{LDH}>1000$, or a glucose concentration $<0.4 \mathrm{~g} / \mathrm{L}$, and signs of infection (fever, biological inflammatory syndrome).

Exclusion criteria were subjects minor or without a pleural sample realized.

PF was immediately examined for Gram-stain and inoculated for aerobic and anaerobic growth. Antimicrobial susceptibility was tested by disks, according to the French guidelines. Resistance to different antibiotics was defined by resistance in vitro of at least a strain among the germ (s) found (s) in the samples.

Pleural infection was considered nosocomial if it did not exist or was not incubating prior to hospital admission. It was secondary to a pleural gesture burglary or to nosocomial pneumonia. Otherwise, infections were considered community-acquired.

\section{Data Collected}

Subjects were identified using the Fusion F software program. The following parameters were collected; age, gender, underlying disease (including cancer, diabetes, neurological disease advanced, heart

*Corresponding author: Sébastien Champion, Department of Medical and Toxicological Intensive Care Unit, Lariboisière University Hospital, 75010 Paris, France, Tel: 00331-49958442; Fax: 00331-49958964; E-mail: champion.seb@wanadoo.fr

Received May 11, 2015; Accepted August 12, 2015; Published August 17, 2015

Citation: Champion S, Annonay M (2015) Resistance to Co-Amoxiclav (Augmentin) in Community-Acquired and Nosocomial Pleural Infections. J Pulm Respir Med 5 284. doi:10.4172/2161-105X.1000284

Copyright: (C) 2015 Champion S, et al. This is an open-access article distributed under the terms of the Creative Commons Attribution License, which permits unrestricted use, distribution, and reproduction in any medium, provided the original author and source are credited. 
failure, chronic renal failure, cirrhosis, chronic respiratory failure, long-term corticosteroids treatment, transplantation, HIV/AIDS, malignant hematology disease, chemotherapy) or another past history (including chronic alcoholism, smoking, malnutrition, antecedent of thoracic surgical or trauma), previous antibiotic administration in the 14 days prior to admission, hospitalization, and nosocomial or community-acquired infection. Clinical data (respiratory functional signs, temperature, blood pressure, heart rate, respiratory rate, oxygen saturation), biological data (number of white blood cells, hemoglobin, albumin, red blood cell counts, distribution width, C-reactive protein, alkaline phosphatase, lactate dehydrogenase), and radiological findings (side of achievement, volume) were reported.

PF: pH, lactate dehydrogenase, glucose, white cell and neutrophil counts, bacteriological findings (direct examination; cultures, and in vitro antimicrobial sensitivity with in particular, the 'first line' antibiotic resistance).

Support: antibiotic therapy, clinical efficacy (apyrexia timeout defined as obtaining a temperature $<37.8^{\circ} \mathrm{C}$ during $48 \mathrm{~h}$ ), duration of stay in ICU, in-hospital survival, complications (loculation, sepsis, infection from another site...), pleural fibrinolysis, surgery.

\section{Statistical analysis}

Data are expressed as median (IQR: 25; 75 percentiles) for continuous variables and number (percent) for binary variables. Qualitative values were compared with Chi-2 tests and quantitative values with Mann-Whitney tests as appropriate. Odds ratios (OR) for hospital mortality were calculated with their $95 \%$ confidence intervals (CI). A p value $<0.05$ was considered significant. Statistical analysis was performed with Statview 5.0.

\section{Results}

\section{Subjects}

During the 6 year-period of time 57 subjects were included (Table 1). They had a significant underlying pathology for 34 of them $(60 \%)$ including: cancer $(n=5)$; malignant hemopathy $(n=3)$; chemotherapy $(\mathrm{n}=3)$; long-lasting corticosteroid therapy $(\mathrm{n}=3)$; previously known AIDS $(n=4)$; diabetes mellitus $(n=9)$; respiratory $(n=4)$, heart $(n=9)$, or renal $(n=4)$ failure; hepatic cirrhosis $(n=1)$; advanced neurological disease $(n=9)$. It was not noted pleural infection related to druginduced aspiration or to thoracic surgery.

Prior to admission, 23 subjects $(40 \%)$ received antibiotics for a median duration of 7 days $(5 ; 11)$. Most of the subjects had communityacquired infections (91\%). Pleural infection was classified nosocomial in 5 subjects (9\%). PF was bilateral in two subjects. The side of pleural infection was not recorded in one subject. PF concerned the right and left side in 35 and 23 subjects (62\% and $41 \%)$ respectively. The outpouring was considered of small $(n=7)$, medium $(n=34)$ or large $(n=15)$ abundance, in 56 subjects for which chest imagery was available. PF was collected in all the subjects. The characteristics of the PF are summarized in Table 2.

\section{Microbiology}

While 23 subjects were on antibiotics prior to admission, at least one microorganism was found in 39 subjects (68\%). For these subjects, the number of responsible microorganisms was one (30 subjects), two (8 subjects), and four (1 subject). Found microorganisms are described in Table 3, depending on nosocomial $(n=5)$ or community-acquired infection ( $\mathrm{n}=34$ found germs on 52 community-acquired empyema). No fermenting Gram-negative bacilli (GNB) (Pseudomonas aeruginosa,

\begin{tabular}{|c|c|}
\hline & Population $(n=57)$ \\
\hline Male (\%) & $36(63 \%)$ \\
\hline Age (years) & $54(40 ; 69)$ \\
\hline Underlying pathology (\%) & $34(60 \%)$ \\
\hline Malnutrition (\%) & $15(26 \%)$ \\
\hline Alcoholism (\%) & $10(18 \%)$ \\
\hline Smoking (\%) & $24(42 \%)$ \\
\hline Thoracic antecedent (\%) & $5(9 \%)$ \\
\hline SAPS $\|^{*}$ & $27(21 ; 42)$ \\
\hline APACHE II ${ }^{\dagger}$ & $11(8 ; 17)$ \\
\hline Temperature $\left({ }^{\circ} \mathrm{C}\right)$ & $38(37.4 ; 38.4)$ \\
\hline Heart rate (/min) & $105(90 ; 116)$ \\
\hline \multicolumn{2}{|l|}{ Blood pressure $(\mathrm{mmHg})$} \\
\hline - Systolic & $120(108 ; 135)$ \\
\hline - diastolic & $70(60,77)$ \\
\hline $\mathrm{SpO}_{2}(\%)^{\ddagger}$ & $96(95 ; 99)$ \\
\hline Respiratory rate (/min) & $30(22 ; 35)$ \\
\hline Leukocyte count $\left(/ \mathrm{mm}^{3}\right)$ & $12700(10000,18000)$ \\
\hline Hemoglobin (g/L) & $112(89 ; 121)$ \\
\hline Red blood cells distribution width & $13.2(12.6 ; 14.6)$ \\
\hline Platelet count & $382(277 ; 567)$ \\
\hline $\mathrm{CRP}(\mathrm{mg} / \mathrm{L})^{\S}$ & $240(147 ; 314)$ \\
\hline Plasma albumin (g/L) & $20(16 ; 26)$ \\
\hline Plasma LDH\| & $252(206 ; 299)$ \\
\hline Alkaline phosphatase & $122(87 ; 212)$ \\
\hline Septic shock (\%) & $6(11 \%)$ \\
\hline Respiratory distress (\%) & $19(33 \%)$ \\
\hline Chest tube drainage $(\%)$ & $50(88 \%)$ \\
\hline Use intra-pleural fibrinolysis (\%) & $27(47 \%)$ \\
\hline Use of thoracic surgery (\%) & $11(19 \%)$ \\
\hline \multicolumn{2}{|l|}{ Length of stay (days) } \\
\hline - Intensive care unit & $7(4,10)$ \\
\hline - Hospital & $18(15 ; 30)$ \\
\hline Invasive mechanical ventilation (\%) & $9(16 \%)$ \\
\hline Duration of ventilation (days) & $5(3 ; 11)$ \\
\hline Hospital mortality (\%) & $5(9 \%)$ \\
\hline
\end{tabular}

*SAPS II, simplified acute physiology score II; ${ }^{\dagger}$ APACHE II, acute physiology and chronic health evaluation $\mathrm{II} ;{ }^{\ddagger} \mathrm{SpO}_{2}$, percutaneous oxygen saturation; ${ }^{\circledR} \mathrm{CRP}$, C-reactive protein; "LDH, lactate dehydrogenase.

Table 1: Demographic characteristics of the overall population (57 patients) with pleural infection.

Stenotrophomonas maltophilia or Acinetobacter sp) or S. aureus resistant to Methicillin were found. Enterobacteriaceae were divided in: Group 1 (4 Escherichia coli, 1 Proteus mirabilis), group 2 (2 Citrobacter koseri, 2 Klebsiella pneumoniae, 1 Klebsiella oxytoca), group 3 (1 Citrobacter freundii, 1 Enterobacter cloacae).

Eight subjects had infection with at least a germ resistant to coamoxiclav, corresponding to $21 \%$ of the subjects with PF positivity $(8 / 39)$ and $14 \%$ of our cohort (8/57). Microorganisms resistant to coamoxiclav were the following: Mycobacterium tuberculosis $(\mathrm{n}=2), E$. cloacae $(\mathrm{n}=1)$, E. coli $(\mathrm{n}=1)$, Enterococcus faecium $(\mathrm{n}=1)$, S. epidermidis $(\mathrm{n}=1)$, and Candida albicans $(\mathrm{n}=2)$. Fungal infections were observed in one AIDS subject with nosocomial infection and in a subject with community-acquired polymicrobial infection (four microorganisms). Excluding fungi and Mycobacteria, "multi-resistant" bacteria were found ( $\mathrm{n}=4$ in 3 subjects) in the community-acquired group and during year 2011 and 2012 (i.e. two last years of survey): E. cloacae with derepressed cephalosporinase $(\mathrm{n}=1)$, E. coli $(\mathrm{n}=1)$ with extended- 


\begin{tabular}{|l|l|l|}
\hline & N & Pleural fluid \\
\hline $\mathrm{pH}$ & 11 & $7.5(7.37 ; 7.9)$ \\
\hline Glucose $(\mathrm{mg} / \mathrm{dL})$ & 49 & $220(30 ; 482)$ \\
\hline Proteins $(\mathrm{g} / \mathrm{L})$ & 51 & $45(33 ; 52)$ \\
\hline LDH $^{*}$ & 34 & $\begin{array}{l}3709(615 ; \\
9258)\end{array}$ \\
\hline Leukocytes & & \\
\hline - neutrophils & & $\begin{array}{l}815(295 ; \\
11880)\end{array}$ \\
\hline - lymphocytes & 42 & $144(49 ; 500)$ \\
\hline
\end{tabular}

* $\mathrm{LDH}$, lactate dehydrogenase

Table 2: biochemical and cytological features in pleural fluid in patients $(N=57)$ in whom it was performed.

\begin{tabular}{|c|c|c|c|}
\hline & $\begin{array}{c}\text { Community-acquired } \\
\text { empyema }(n=52)\end{array}$ & $\begin{array}{c}\text { Nosocomial } \\
\text { empyema }(n=5)\end{array}$ & p value \\
\hline Antibiotic $<1$ month & $20(38 \%)$ & $3(60 \%)$ & 0.3 \\
\hline Gram stain & $18(35 \%)$ & $4(80 \%)$ & $0.047^{*}$ \\
\hline Positive culture & $20(38 \%)$ & $4(80 \%)$ & 0.07 \\
\hline Gram-positive cocci & $25 / 34(74 \%)$ & $2(40 \%)$ & 0.7 \\
\hline $\begin{array}{l}\text { - aerobic Streptococcus } \\
\text { (non pneumoniae) }\end{array}$ & $9 / 34(26 \%)$ & 0 & - \\
\hline $\begin{array}{l}\text { - Streptococcus } \\
\text { pneumoniae }\end{array}$ & $15 / 34(44 \%)$ & 0 & - \\
\hline - Anaerobic Streptococcus & $3 / 34(9 \%)$ & 0 & - \\
\hline - Staphylococcus aureus & $2 / 34(6 \%)$ & $2(40 \%)$ & $0.02^{*}$ \\
\hline $\begin{array}{l}\text { - Non-aureus } \\
\text { Staphylococcus }\end{array}$ & $1(3 \%)$ & 0 & - \\
\hline Gram-negative bacilli & $11 / 34(32 \%)$ & $2(40 \%)$ & 0.3 \\
\hline \multicolumn{4}{|l|}{ Enterobacteria group } \\
\hline-1 & $3(9 \%)$ & $1(20 \%)$ & 0.2 \\
\hline-2 & $3(9 \%)$ & $2(40 \%)$ & $0.01^{*}$ \\
\hline-3 & $2(6 \%)$ & 0 & - \\
\hline Other anaerobes & $2 / 34(6 \%)$ & 0 & - \\
\hline Candida albicans & $1(3 \%)$ & $1(20 \%)$ & $0.04^{*}$ \\
\hline $\begin{array}{l}\text { Mycobacterium } \\
\text { tuberculosis }\end{array}$ & $2(6 \%)$ & 0 & - \\
\hline Resistance to penicillin G & $12 / 34(35 \%)$ & $4(80 \%)$ & 0.1 \\
\hline Resistance to amoxicillin & $12 / 34(35 \%)$ & $3(60 \%)$ & 0.2 \\
\hline $\begin{array}{l}\text { Resistance to co- } \\
\text { amoxiclav }\end{array}$ & $7 / 34(21 \%)$ & $1(20 \%)$ & 1 \\
\hline \multicolumn{4}{|l|}{$\begin{array}{l}\text { Resistance to } \\
\text { cephalosporins }\end{array}$} \\
\hline$-1^{\text {era }}$ generation & $7 / 34(21 \%)$ & $1(20 \%)$ & 1 \\
\hline$-2^{\text {nd }}$ generation & $6 / 34(18 \%)$ & $1(20 \%)$ & 1 \\
\hline$-3^{\text {rd }}$ generation & $6 / 34(18 \%)$ & $1(20 \%)$ & 1 \\
\hline Resistance to clindamycin & $10 / 34(29 \%)$ & $3(60 \%)$ & 0.2 \\
\hline Fluoroquinolone resistance & $9 / 34(26 \%)$ & $1(20 \%)$ & 0.8 \\
\hline No germ & $5(15 \%)$ & $1(20 \%)$ & 0.5 \\
\hline $\begin{array}{l}\text { Unfavourable evolution of } \\
\text { Empyema }\end{array}$ & $10(19 \%)$ & $2(40 \%)$ & 0.3 \\
\hline Complication & $42(81 \%)$ & $5(100 \%)$ & 0.3 \\
\hline Death & $2(4 \%)$ & $3(60 \%)$ & $0.001^{*}$ \\
\hline
\end{tabular}

${ }^{*} \mathrm{p}<0.05$.

Table 3: Bacteriological data of pleural fluid according to the community-acquired $(n=52$ whose 34 germs were found) and nosocomial $(n=5$ whose 4 germs were found) origins of the pleural infection.

spectrum beta-lactamase, Enterococcus faecium resistant to ampicillin and a S. epidermidis resistant to Methicillin. As a whole 3 out of 57 (5\%) subjects had microorganisms (not including candida and mycobacteria) resistant to co-amoxiclav.

Nosocomial thoracic empyema had more S. aureus, Group 2
Enterobacteriaceae, and C. albicans ( $\mathrm{p}<0.05$ for each) than communityacquired thoracic empyema. The rate of resistance to co-amoxiclav was equivalent to that observed for the community-acquired empyema ( $20 \%$ and $14 \%$ respectively).

\section{Antibiotics and efficacy}

All subjects received antibiotics from admission. Subjects were treated with co-amoxiclav $(\mathrm{n}=21)$, and/or another antibiotics $(\mathrm{n}=50)$. After admission, initiation of in vitro effective antibiotic therapy was $<24$ hours in 48 subjects (84\%). Apyrexia was obtained after 1 day (0; 3). Noteworthy, despite administration of antibiotics and frequent chest tube drainage, unfavorable development of empyema (encystment, loculation, and lung abscess) was noted during the course in 45 subjects (79\%).

\section{Prognosis}

Nosocomial empyema was more frequent in subjects with shock ( $\mathrm{OR}=8$, CI 1.02-62, $\mathrm{p}=0.047)$, intubation ( $\mathrm{OR}=11$, CI 1.6-83, $\mathrm{p}=0.02)$, anemia (Hemoglobin 88 vs. $122 \mathrm{gr} / \mathrm{L}, \mathrm{p}=0.01$ ), and who received extended prior antibiotic therapy (for 28 vs. 6 days, $\mathrm{p}=0.02$ ). These parameters were associated with a clear increased risk of in-hospital deaths in subjects with nosocomial empyema ( $\mathrm{OR}=37$, CI 3.8-367, $\mathrm{p}=0.002$ ). Several other items were related to an increase in mortality rate without being bound to the nosocomial infection factor, including: a higher Simplified Acute Physiology Score II (SAPS II), and Acute Physiology And Chronic Health Evaluation II (APACHE II) scores ( 50 vs. $27, \mathrm{p}=0.006$ and 28 vs. $10, \mathrm{p}=0.003$, respectively), malnutrition ( $\mathrm{OR}=15$, CI 1.5-143, $\mathrm{p}=0.02)$, and advanced neurological disease $(\mathrm{OR}=6$, CI 1.02-42, $\mathrm{p}=0.048)$. Interestingly, intra-pleural fibrinolysis was associated with a favorable outcome (27 fibrinolysis / 52 survivors vs. 0 fibrinolysis in 5 non-survivors, $\mathrm{p}=0.03$ ).

\section{Discussion}

\section{Microbiology, antibiotics and prognosis}

Refreshing or updating microbiological data seems essential to guide the probabilistic antibiotic therapy in pleural infection. Our study is consistent with the predominance of Gram-positive cocci in community-acquired pleural infections $[4,6]$, even if $60 \%$ of our subjects had an underlying disease, increasing the risk of GNB and fungal infection [14]. The rate of PF bacterial "negativity" (32\%) found in the present study is also in agreement with previous studies that consistently reported rates of negative PF of about 40 to $50 \%[1,12]$.

Our study found resistance to a first line antibiotic - co-amoxiclav in $14 \%$ of so-called community-acquired subjects and in $21 \%$ of the PF with bacteriological growth. The differences between nosocomial and community-acquired thoracic empyema included a predominance of infection with $S$. aureus and group 2 enterobacteria in the nosocomial empyema, also found by others $[5,15]$. We cannot recommend more judicious antimicrobial therapy in the light of our ecology. However, a probabilistic antibiotic with co-amoxiclav is questionable, even in community-acquired empyema. Accordingly, adequate coverage based on in vitro susceptibility of micro-organisms found in communityacquired and nosocomial pleural infections, was reported to be only $52 \%$ ( $49 \%$ to $53 \%)$ and $84 \%$ ( $78 \%$ to $86 \%)$ with the association of metronidazole and either penicillin (Scandinavian recommended antimicrobial therapy) or cefuroxime, respectively [5].

Tuberculosis infection did not appear to be a concern regarding the immediate risk of sepsis (mortality $0 / 3,0 \%$ in a medical ICU) [9]. On the other hand, the fungal infection was a real threat, even 
among the immune-competent subjects (mortality $2 / 2100 \%$, in the same series [9]. One of our subjects with AIDS exhibited C. albicans empyema after staying for a long period in hospital and died rapidly. However, the appropriate antifungal treatment was delayed by 2 days. The role of resistant Gram-positive cocci (ampicillin-resistant $E$. faecium and Methicillin-resistant S. epidermidis in our cohort) and GNB (Enterobacteriaceae with derepressed cephalosporinase and extended-spectrum beta-lactamase) to front-line antibiotics should be highlighted in the community-acquired empyema in our study.

Before severe sepsis and septic shock related to purulent empyema, especially if the patient has received extended antibiotic therapy, broad-spectrum antibiotic therapy should be recommended, pending the results of the direct examination and culture of PF (and blood), as acknowledged by Tu and colleagues. In immunocompromised patients, the use of the antifungal therapy (fluconazole), especially for nosocomial empyema should be discussed $[1,9,16]$. Finally, an emergence of drug resistant bacteria is a possible mechanism, as those micro-organisms were found only in the last two years of our study [10].

However, despite delay in administration of adequate antimicrobial therapy, mortality remained lower in our subjects than that observed in severe complicated parapneumonic effusions ( $9 \%$ vs. $48 \%)$ and this discrepancy is questionable [9]. First, population may differ between the centers with different inclusion criteria. Our subjects rarely received catecholamines $(11 \%)$ or mechanical ventilation $(16 \%)$. Subjects were admitted in our ICU if chest tube drainage was needed. Though, our subjects did not represent a real ICU population with subsequent elevated mortality, but is in agreement with previous reports accounting for by mortality rates of about $4.7 \%$ to $27 \%$, in patients with complicated pleural effusions $[5,15,17]$. Maskell found a 12 -month mortality rate of about $22 \%$, with a significant increase in patients with nosocomial infections (45\%; OR 4.24), the mortality rates increased when S. aureus, GNB, or mixed aerobic bacteria where found, compared to anaerobes, Streptococcal, or culture-negative infections [6].

Although Tu et al did not report the adequation of "standard" antimicrobial therapy, they reported many "resistant" GNB (fermenting or group 3) along with fungi and a $36 \%$ rate of inadequate initial antimicrobial therapy in non-tuberculosis bacteriologically proven pleural infection [9]. The inadequacy between initial antibiotics and in vitro findings was associated with a $60 \%$ increase in the mortality rate. Though, their susceptibility to antibiotics antimicrobial therapy might have been even lower than ours. Finally, in contrast with lung infection [18], delay in adequate antimicrobial therapy in PF may not be the point [17], as chest tube drainage is an effective treatment to quickly decrease bacterial load and improve the patients' condition [19-21]. However, some authors recommend not draining every complicated pleural effusion [22]. Accordingly, although ICU patients aforementioned had small bore pleural pigtail catheter, their need for chest tube drainage, intra-pleural fibrinolysis and thoracic surgery was particularly low (9\%, $4 \%$ and $4 \%$ respectively), rendering the characteristics of the pleural infection and its management different from ours. On the other hand, a study found a significant association between adequate empirical therapy and a decrease in hospital mortality (OR 0.43; $\mathrm{p}=0.02)$ in the multivariate analysis, consistent with the results of our study [5].

Intra-pleural fibrinolysis with streptokinase resulted in disappointing results [23]. However, the same team showed that adjunction of deoxyribonuclease with recombinant tissue plasminogen activator improved the drainage of infected PF and subsequently decreased the need for thoracic surgery and hospital stay with no change in the mortality rate [24]. Fibrinolysis was realized without deoxyribonuclease (not available in our hospital) and did not reduce the need for surgery, in our series. However, it was associated with a lower mortality rate, such as in sub-groups of proven loculated/septated effusions in a systematic review [25]. This review showed a significant reduction in surgical intervention. Nevertheless, our retrospective study did not allow concluding on the benefit of fibrinolysis, in terms of mortality or surgical requirements.

The other elements associated with hospital mortality were common. We did not find significant association between red blood cells distribution width or alkaline phosphatase and mortality [15]. However, those variables do not seem valuable tools for prognosis assessment in thoracic empyema. According to pulmonary vasculature and pleural drainage, we found a right predominance as expected [15].

\section{Limitations}

Our study is an overview of the ecology of a small series of subjects admitted for empyema thoracis and complicated pleural effusion in a single ICU. It is only a local vision and cannot be extended to the whole spectrum of purulent empyema. Diagnoses on admission were variable and population heterogeneous. Our hospitals having no facility for thoracic surgery, the rare nosocomial thoracic empyema were probably the consequences of complicated pulmonary infections and were not the image of post-operative direct inoculations. However, given the low rate of S. aureus resistant to Methicillin and Streptococcus pneumoniae with decreased susceptibility in France, our results might encourage other countries screening for bacterial resistance in communityacquired pleural infections.

$\mathrm{PF}$ had different characteristics than previous studies $[6,17,20]$. $\mathrm{PF} \mathrm{pH}$ and glucose were higher, though, false positive of PF culture might account for misdiagnosis. However, previous studies reported that some patients with $\mathrm{PF} \mathrm{pH}>7.2$ do need tube thoracostomy or decortication [26]. Moreover, every subject had clinical signs of overt pleural infection in our series. Clinicians should take into account PF culture despite elevated $\mathrm{PF} \mathrm{pH}$ and glucose, if clinically indicated [17].

\section{Conclusion}

Our study found a resistance to co-amoxiclav in $14 \%$ of the subjects with community-acquired thoracic pleural infection and in $21 \%$ of found microorganisms. There was no evidence of notable difference in spectrum's between nosocomial and community-acquired pleural infection.

\section{Acknowledgement}

Dr Isabelle Malissin and Pr Frédéric J. Baud for critical review.

\section{References}

1. Ahmed RA, Marrie TJ, Huang JQ (2006) Thoracic empyema in patients with community-acquired pneumonia. Am J Med 119: 877-883.

2. Bartlett JG, Gorbach SL, Thadepalli H, Finegold SM (1974) Bacteriology of empyema. Lancet 1: 338-340.

3. Civen R, Jousimies-Somer H, Marina M, Borenstein L, Shah H, et al. (1995) A retrospective review of cases of anaerobic empyema and update of bacteriology. Clin Infect Dis 20 Suppl 2: S224-229.

4. Brook I, Frazier EH (1993) Aerobic and anaerobic microbiology of empyema. A retrospective review in two military hospitals. Chest 103: 1502-1507.

5. Meyer CN, Rosenlund S, Nielsen J, Friis-Møller A (2011) Bacteriological aetiology and antimicrobial treatment of pleural empyema. Scand J Infect Dis 43: 165-169.

6. Maskell NA, Batt S, Hedley EL, Davies CW, Gillespie SH, et al. (2006) The bacteriology of pleural infection by genetic and standard methods and its 
Citation:Champion S, Annonay M (2015) Resistance to Co-Amoxiclav (Augmentin) in Community-Acquired and Nosocomial Pleural Infections. J Pulm Respir Med 5: 284. doi:10.4172/2161-105X.1000284

mortality significance. Am J Respir Crit Care Med 174: 817-823.

7. Davies CW, Gleeson FV, Davies RJ (2003) Pleural Diseases Group Standards of Care Committee, British Thoracic Society: BTS guidelines for the management of pleural infection. Thorax 58 Suppl 2: ii18-28.

8. Boles JM, Saulnier F, Jaeger A, Offenstadt G, Bollaert PE, et al. (2000) Collège National des Enseignants de Réanimation. Réanimation médicale, 2ème édition. Elsiever/Masson, Rabbat A, Faisy C, Laaban JP. Pathologies pleurales.

9. Tu CY, Hsu WH, Hsia TC, Chen HJ, Chiu KL, et al. (2006) The changing pathogens of complicated parapneumonic effusions or empyemas in a medical intensive care unit. Intensive Care Med 32: 570-576.

10. Bender JM, Ampofo K, Sheng X, Pavia AT, Cannon-Albright L, et al. (2009) Parapneumonic empyema deaths during past century, Utah. Emerg Infect Dis 15: 44-48.

11. Ozol D, Oktem S, Erdinc E (2006) Complicated parapneumonic effusion and empyema thoracis: microbiologic and therapeutic aspects. Respir Med 100: 286-291

12. Alfageme I, Muñoz F, Peña N, Umbría S (1993) Empyema of the thorax in adults. Etiology, microbiologic findings, and management. Chest 103: 839-843.

13. Geha AS (1971) Pleural empyema. Changing etiologic, bacteriologic, and therapeutic aspects. J Thorac Cardiovasc Surg 61: 626-635.

14. Vianna NJ (1971) Nontuberculous bacterial empyema in patients with and without underlying diseases. JAMA 215: 69-75.

15. Marks DJ, Fisk MD, Koo CY, Pavlou M, Peck L, et al. (2012) Thoracic empyema: a 12-year study from a UK tertiary cardiothoracic referral centre. PLoS One 7: e30074.

16. Ko SC, Chen KY, Hsueh PR, Luh KT, Yang PC (2000) Fungal empyema thoracis: an emerging clinical entity. Chest 117: 1672-1678.

17. Davies CW, Kearney SE, Gleeson FV, Davies RJ (1999) Predictors of outcome and long-term survival in patients with pleural infection. Am J Respir Crit Care Med 160: 1682-1687.

18. Leroy O, Meybeck A, d'Escrivan T, Devos P, Kipnis E, et al. (2003) Impact of adequacy of initial antimicrobial therapy on the prognosis of patients with ventilator-associated pneumonia. Intensive Care Med 29: 2170-2173.

19. Colice GL, Curtis A, Deslauriers J, Heffner J, Light R, et al. (2000) Medical and surgical treatment of parapneumonic effusions : an evidence-based guideline. Chest 118: 1158-1171.

20. Ashbaugh DG (1991) Empyema thoracis. Factors influencing morbidity and mortality. Chest 99: 1162-1165.

21. Sasse S, Nguyen TK, Mulligan M, Wang NS, Mahutte CK, et al. (1997) The effects of early chest tube placement on empyema resolution. Chest 111: 16791683.

22. Berger HA, Morganroth ML (1990) Immediate drainage is not required for all patients with complicated parapneumonic effusions. Chest 97: 731-735.

23. Maskell NA, Davies CW, Nunn AJ, Hedley EL, Gleeson FV, et al. (2005) U.K. Controlled trial of intrapleural streptokinase for pleural infection. N Engl J Med 352: 865-874.

24. Rahman NM, Maskell NA, West A, Teoh R, Arnold A, et al. (2011) Intrapleura use of tissue plasminogen activator and DNase in pleural infection. $\mathrm{N}$ Engl $\mathrm{J}$ Med 365: 518-526

25. Cameron R, Davies HR (2008) Intra-pleural fibrinolytic therapy versus conservative management in the treatment of adult parapneumonic effusions and empyema. Cochrane Database Syst Rev : CD002312.

26. Poe RH, Marin MG, Israel RH, Kallay MC (1991) Utility of pleural fluid analysis in predicting tube thoracostomy/decortication in parapneumonic effusions. Chest 100: 963-967. 